\title{
“EL TREN QUE NUNCA LLEGÓ A TIEMPO”, "EL SONIDO DE TU CUERPO”, “ÁNGULO RECTO”, “EL BAILE DE LA LIBERTAD”, “SOLEDADES" y "NO LLORES POR MÍ CUANDO ME MUERA" 1
}

\author{
Belén Olavarría ${ }^{2}$
}

\section{El tren que nunca llegó a tiempo}

Hay gente que dice que cuando Dios te cierra una puerta

siempre te abre una ventana.

No sé hasta qué punto esa frase es cierta,

o si más bien Dios se dedica a vernos pasar

como trenes a los que nunca llega a tiempo

sintiéndose, durante el primer instante, culpable por no haber estado allí,

y, al minuto, despreocupado de lo que aconteciera mientras él no lo hubiera visto.

Así me sentía yo,

esperando lo que creía que debía esperar,

creyendo a ciegas en la fe de un destino

que al parecer todos poseemos,

como un gen del que no te puedas despegar.

Incauta.

Esperando...

${ }^{1}$ Fecha de recepción: 22/12/2016.

Fecha de aceptación: 23/12/2016.

${ }^{2}$ Poeta sevillana, accésit en el V Certamen Internacional de Poesía Yolanda Sáenz de Tejada y finalista en el concurso Be Brave Festival 2015-Contra la violencia de género, es autora del libro de micropoemas Poeta en la red y participa en la antología solidaria Luces y sombras. Ha publicado sus poemas en diversas revistas y blogs literarios, participando de forma activa en diversos actos poéticos con la asociación literaria Noches del Baratillo, de la cual es miembro, con los Circuitos de Exposiciones Itinerantes de Sevilla o con la emisora Radio Triana. De forma adicional, colabora periódicamente con sus poemas en Onda Sevilla Radio; $\bowtie$ olavarria.belen@gmail.com. 
Solitaria.

Esperando...

Ociosa.

Esperando...

Se supone que hay gente que dice que cada vez que Dios cierra una puerta abre una ventana.

No sé cuántas personas habrán probado a tirarse al vacío a través de una de ellas sin ser consciente de la altura a la que te encuentras.

Así me encontraba yo,

pero en vez de una puerta

se me cerraba el acceso a mi morada,

y en lugar de una ventana

era un agujero pequeño,

un hueco chiquitito e inaccesible,

una maloliente ratonera

a la que me daban paso,

como si ya no hubiera nada más que hacer por mí.

Como si mi vida fuera ese tren

que Dios dejó pasar sin darse cuenta.

\section{El sonido de tu cuerpo}

¿Dónde estás?

¿Por qué no te veo?

Si siento las luces de tu corazón latiendo;

$\tan$ cerca,

$\tan$ lejos,

me hacen creer 
lo que no quiero.

Ruido detrás del cajón que no cierro,

agua salada

que de mi voz destierro.

Siento tus manos, denotan el miedo.

Acarician el aire que después yo me bebo,

recorriendo en tu risa

la felicidad de tu cuerpo.

Y sé cómo será tu rostro a mi edad,

crece en mis recuerdos.

Dónde vivirás,

el color de tu casa,

la carrera que estudias;

he visto todos tus méritos.

Y viajarás por el mundo sacando en otros lo bueno,

lo sé,

tal y como siempre hiciste.

Aunque quizás...

tanto no podremos vernos,

pero sé que cuando vuelvas

será como siempre,

como si nunca te hubieses ido.

Porque sé que volverás...

Y si no quieres que así sea.

Si no quieres irte.

Si quieres quedarte conmigo,

yo estaré aquí, 
avivando tus recuerdos,

avivando tus latidos,

a tu corazón que, aunque ya no esté,

aún acompasa al mío.

\section{Ángulo recto}

En la mesa,

ángulo recto con tu brazo,

veo caer las hojas

que escribes con desánimo.

En la mesa,

ángulo recto con tu espalda,

veo morir los versos

que al aire lanzas.

\section{El baile de la libertad}

El día que salimos de la guerra

paseamos por una calle gris llena de cocheras.

El sol aún estaba por brillar,

y no había dinero para encender las farolas;

pero nos contentamos con ver los nidos de los pájaros

instaurados en los bajos de balcones de hormigón,

y a las golondrinas revolotear

en un baile que se nos antojaba el de la libertad. 


\section{Soledades}

Me gustan las personas que se sientan solas en las terrazas de los bares con la mirada clavada en el pasado.

Y de cuando en cuando, observan a los transeúntes con una mezcla de curiosidad y estoicismo, como si la simple presencia de un extraño fuera capaz de fulminar sus soledades.

\section{No llores por mí cuando me muera}

No llores por mí cuando me muera.

Llora cuando me halles muerta en vida;

cuando tus palabras me alejen de mi camino;

cuando las críticas me hundan en profundos lamentos.

Apénate de mí, cuando el azar me golpee y magulle mis heridas.

Cuando crea que todo lo malo terminó

y sin embargo, sólo era el comienzo.

No llores por mí cuando me muera.

Y finalmente, tampoco cuando viva,

porque tus lágrimas no aliviarán mi pena. 